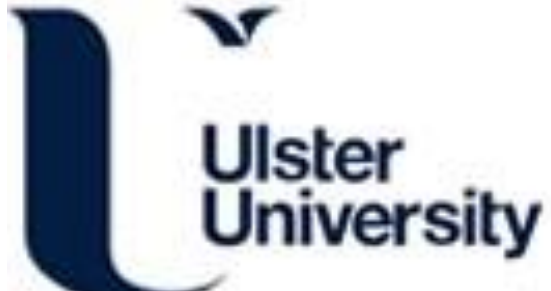

\section{Observed site obstacle impacts on the energy performance of a large scale urban wind turbine using an electrical energy rose}

Byrne, R., Hewitt, N., Griffiths, P., \& MacArtain, P. (2018). Observed site obstacle impacts on the energy performance of a large scale urban wind turbine using an electrical energy rose. Energy for Sustainable Development, 43, 23-37. https://doi.org/10.1016/j.esd.2017.12.002

Link to publication record in Ulster University Research Portal

\section{Published in:}

Energy for Sustainable Development

Publication Status:

Published (in print/issue): 30/04/2018

DOI:

10.1016/j.esd.2017.12.002

\section{Document Version}

Author Accepted version

\section{General rights}

Copyright for the publications made accessible via Ulster University's Research Portal is retained by the author(s) and / or other copyright owners and it is a condition of accessing these publications that users recognise and abide by the legal requirements associated with these rights.

\section{Take down policy}

The Research Portal is Ulster University's institutional repository that provides access to Ulster's research outputs. Every effort has been made to ensure that content in the Research Portal does not infringe any person's rights, or applicable UK laws. If you discover content in the Research Portal that you believe breaches copyright or violates any law, please contact pure-support@ulster.ac.uk. 
1 Observed site obstacle impacts on the energy performance of a large scale 2 urban wind turbine using an electrical energy rose

3

4

5

6

\author{
Raymond Byrne a,b, Neil J Hewitt b, Philip Griffiths ${ }^{\mathrm{b}}$, Paul MacArtain a \\ a Centre for Renewables \& Energy, Dundalk Institute of Technology, Dundalk, Republic of Ireland \\ b Centre for Sustainable Technologies, School of the Built Environment, University of Ulster, Belfast, Northern Ireland
}

\title{
ABSTRACT
}

Large scale wind turbines deployed in "behind the meter" applications at medium and large scale industrial consumer sites can offset the purchase of retail electricity from the utility. However, unlike traditional onshore wind farm sites in elevated rural areas, such industrial sites tend to be at lower elevations and located in more urbanised areas with a higher likelihood of being in vicinity of manmade obstacles such as buildings. This research case study presents observed impacts of various site obstacle features, from local buildings to regional topography on the energy performance of an 850kW rated wind turbine operating in a peri-urban area. The study is based on the analysis of 10-minute SCADA data measured over multiple years. The analysis includes a novel wind turbine electrical energy rose (EER) approach to determine the directional variation of the wind turbine electrical energy output in relation to site features around the turbine location. The paper concludes that low broad buildings with heights of only $20 \%$ of the turbine hub height can have a significant energy reducing impact compared to taller narrow buildings and that hills $\sim 8 \mathrm{~km}$ from the turbine site have an energy reducing impact. The outcomes of the study should be of benefit to those involved in the pre-feasibility stages of deploying single large scale wind turbines at industrial sites in peri-urban areas.

Key Words: Wind resource; Wind turbines; Micro-siting; Behind the meter wind; Power performance; Wind autoproduction;

\section{Introduction}

\subsection{Wind Autoproduction}

Globally wind energy has grown substantially in recent decades with an installed capacity at the end of 2016 of 486.8GW (GWEC, 2016). The vast majority of this capacity is both in rural onshore wind farm developments and growing offshore developments using large scale wind turbines. There has been a relatively small contribution from small scale wind systems (i.e. systems less than $100 \mathrm{~kW}$ ) with that latest reported global capacity at end of 2015 standing at 945MW (Pitteloud \& Gsänger, 2017). Wind generation of electricity for onsite consumption, sometimes referred to as "behind the meter" (Lantz, et al., 2016) or "wind autoproduction" (Hanrahan, et al., 2014) is where a wind turbine(s) is connected to the grid at consumer side of the electricity meter thereby offsetting the purchase of retail electricity from the grid i.e. reducing electricity bills while only excess electricity is exported to grid. It can be implemented with small medium or large scale wind turbines depending on consumer demand. (Lantz, et al., 2016), assessed the future market potential of distributed wind in the USA, specifically for behind the meter projects. The study included small, medium scale and a large scale wind turbines. It concluded that the potential for tens of GW of capacity can be realised over time, subject to technology cost reductions and the development new business models with favourable consumer adoption mechanisms. To achieve best energy and economic performance from any wind project careful attention should be given to siting and sizing a wind turbine at the given site, as the energy performance of any wind turbine is sensitive to a number of 
atmospheric parameters such wind speed, wind direction, wind shear, wind veer, turbulence and air density (Bardal, et al., 2015). These parameters can be influenced by local and regional features around the site such as topography, obstacles, general surface roughness and thermal effects (Manwell, et al., 2009). Due to rapid growth in onshore wind in recent years the availability of wind sites of low complexity is becoming limited with onshore wind projects being developed at more complex topographical sites (Zendehbad, et al., 2016) and may include forestry. Behind the meter wind projects are more likely to be at lower elevations in peri-urban and urbanised area that have lower wind speeds and include extra complexities such as building obstacles and higher surface roughness. Few published studies exist on the measured operating performance of medium scale $(100$ to $500 \mathrm{~kW})$ or large scale $(>500 \mathrm{~kW})$ wind turbines in autoproduction applications in relation to complex peri-urban wind environments where wind flow may be heavily influenced by local building obstacles. (Staudt, 2006) published the economic performance of an $850 \mathrm{~kW}$ wind autoproducer at Dundalk Institute of Technology on the east coast of Ireland. The predicted annual energy output values were 2 million $\mathrm{kWh}$ while actual metered energy output was 1.5 million $\mathrm{kWh}$. A further of study by (Cooney, et al., 2017) using 1 year of performance data from 2008 for the same system showed the economics of the project was on a par with a typical wind farm developments due to the offsets in purchase of retail electricity. However, the study also showed overestimates in predicted annual energy output of $\sim 25 \%$ compared to measured annual energy output. (Hildreth \& Kildegaard, 2009) investigated the avoidance of demand charges using a behind the meter $1.65 \mathrm{MW}$ wind turbine i.e. a wind autoproducer at the University of Minnesota in the USA. The focus of the study was on the economic value of power $\mathrm{kW}$ demand reduction from a standing charge point of view i.e. in addition to saving made as result of energy offset. Extrapolated wind speed data from a met mast to the hub height of the turbine was combined with the manufacturer's power curve to estimate the power production of the turbine and concluded a potential extra $10 \%$ cost savings on demand charges. The study assumed a simple power law in the wind data extrapolation from mast height hub height. No site description and its impact on wind turbine were given.

\subsection{Approaches to wind resource assessment}

Wind resource assessment in the prediction of annual energy yield from any given large scale wind project involves onsite wind measurements combined with various modelling approaches depending on the size and complexity of the site. These include, mesoscale numerical weather prediction (NWP) models that simulate a broad range of meteorological phenomena from data reanalysis from the synoptic $(\sim 100-1000 \mathrm{~km})$ to the microscales $(1-10 \mathrm{~km})$ (Zhang, 2015). They give general climate parameters such as annual average wind speed, wind direction distribution, temperature, and air density. NWP are combined with microscale linearised models (e.g. WAsP) and/or computational fluid dynamic (CFD) models for site specific assessment down to $100 \mathrm{~m}$. The modelling approach to use depends on speed, cost and accuracy required in relation to the complexity of the wind project location and the wind project size. The most commonly used CFD models are based on the Reynolds Averaged Navier Stoke's (RANS) equations and Large Eddy Simulation (LES). RANS models parameterize all the turbulence, and resolve only the mean flow. LES models resolve time dependent and spatially averaged NavierStokes equations. LES explicitly resolves the largest eddies but requires very high computing power and is more costly. Detached Eddy Simulation (DES) is a combination of LES and RANS (Dadioti \& Rees, 2017) that uses LES only for regions of separated flow to reduce cost while keeping accuracy. The accuracy of CFD simulations are dependent on many variables such as the modelling approach taken, initial conditions, boundary condition, mesh size, user experience and computation time (Franke, et al., 2011). Accurate wind resource assessment and turbine energy yield prediction at both complex rural and urban sites remains challenging. (Beaucage, et al., 2014) evaluated four numerical wind flow models to assess the variation in wind speed across fours sites of varying terrain complexities, surface characteristics and wind climates. The study found that NWP coupled with LES provided the lowest error compared with measurements and that thermal stability, temperature and moisture gradients developed in the 
NWP mesoscale simulations are very important parameters in understanding atmospheric wind flow. (Bechmann, et al., 2011) carried out a blind comparison of different microscale flow models in flow over real complex terrain against 10 measurement masts on the escarpment of the Bolund peninsula in the Roskilde Fjord in Denmark. The flow models included WAsP, RANS, LES and empirical models from wind tunnel experiments. Significant scatter was observed for both wind speed and turbulence levels among the different models, due to sharp edges in the topographical features concluding that numerical models requires further development. A large blind comparative wind resource assessment study on two Scottish wind farms, involving many industrial and academic organisations, was co-ordinated by Wind Europe (Gylling, et al., 2015). Many different models were used, but on average it was difficult to definitively determine whether linear or CFD modelling approaches gave best results. The broad conclusion was that well defined and validated procedures are needed in order to obtain more reliable results and the choice and configuration of flow model should be based on reliable validation data. A study by (Fields, et al., 2016) on the current state of the industry in the USA regarding distributed wind resource assessment (DWRA) reports that due to the diversity of project sites and turbine sizes there is little agreement on the accuracy of DWRA methods with up to $250 \%$ error. The long term research challenges of wind energy assessed by the European Association of Wind Academics (van Kuik, et al., 2016) identified that as wind turbines are being installed more and more in complex terrain how to generalise an inflow classifications scheme to cover all types of locations is a major challenge.

\subsection{Wind Energy in the Urban Environment}

In recent years the application of wind energy in urban areas has been gaining some interest primarily in the areas of small wind turbine technology (Wang, et al., 2017; Ishugah, et al., 2014; ELMokadem, et al., 2016). Numerous studies (Drew, et al., 2013; Grieser, et al., 2015; Sunderland, et al., 2010; Heath, et al., 2007; Millward-Hopkins, et al., 2013) in urban wind energy to date have focussed on the potential for micro and small scale wind systems (e.g. roof mounted systems) in city environments. A common conclusion is that low average wind speeds, high turbulence, low capacity factors, building mounting structural issues resulting poor economics has hampered the development an urban small scale wind market to date and that further research is required to optimise the locations of micro and small scale systems in urban environments. CFD in the context of the urban wind energy has seen a focus on wind flow around different types of roof tops for wind energy exploitation (Toja-Silva, et al., 2015; Herrmann-Priesnitz, et al., 2015; Wang, et al., 2017). Surface roughness elements in the urban environment may form urban canopies (Peterka, et al., 1985; Belcher, et al., 2003; Mertens, $2006)$ that can result in complex vertical wind speed profiles including vertical displacement, speed up effects, flow separation and re-circulation. CFD modelling approaches in urban environments, though progressing, are still challenging (Franke, et al., 2011). (Cheng, et al., 2003) modelled flow over a matrix of cubes with using both RANS and LES and concluded that RANS modelling gives significant uncertainties in description of unsteady flow phenomena such as flow separation, vortex shedding and recirculation. LES gives more accuracy but is more computational and cost intensive. A need remains for validation of CFD modelling approaches with field measurements (Tabrizi, et al., 2014). Ongoing work in forest canopy environments in complex rural areas is also a major focus of the wind industry though wind flow above and through forest canopies can differ from urban environments due to their porosities, leaf area densities and their seasonal variations (Desmond, et al., 2017). Calculations (da Costa, et al., 2006) with different values of canopy foliage density showed its importance a major source of uncertainty in real forest canopy flows. (Finnigan, 2009) showed that there are differences in the wind flow characteristics over urban and plant canopies due to fundamental differences in turbulence eddy structures that, in the case of plant canopies, are dominated by coherent eddies with distinct length and time scales. 


\subsection{Objectives}

The objective of this study is to investigate a multi-annual measured energy performance of an $850 \mathrm{~kW}$ Vestas V52 wind turbine with a hub height of $60 \mathrm{~m}$ and rotor diameter of $52 \mathrm{~m}$ has been operating as an autoproducer at Dundalk Institute of Technology, located on the east coast of the Republic of Ireland. (53.984ㅇ,-6.392 : WGS 1984 Web_Mercator_Auxillary_Sphere), since October 2005. The turbine is sited in a peri-urban area of low elevation in the vicinity of buildings. The wind turbine SCADA system measures and logs a range of internal system operational and external wind and environmental parameters in 10-minute average values. This data is here analysed to assess the energy performance of the turbine and to give insights into external site factors that have influenced it performance over a multi-annual timeframe. The first part of this study assesses wind roses predicted by the Irish Wind Atlas (Sustainable Energy Authority of Ireland (SEAI), 2015). This atlas is developed from NWP models using ERAInterim reanalyses data from 2001 to 2010 to model hourly wind components on a $4 \mathrm{~km}$ resolution grid, downscaled to $1 \mathrm{~km}$ resolution accounting for land surface roughness. This is compared to the measured wind rose generated from the measured wind turbine SCADA data at this site. Measured directional wind power density, turbulence intensity curves and wind turbine power curves and are also investigated. As electrical energy output (kWh) is of most interest to end users of behind the meter wind systems a novel approach of using an electrical energy rose (EER) to assess the impact of surrounding site obstacles on turbine's directional energy performance is proposed. The measured results are discussed in the context of establishing initial site screening rules in the prefeasibility stages of potential large scale wind turbine installations in urbanised areas.

\section{Methods}

\subsection{Wind turbine site description}

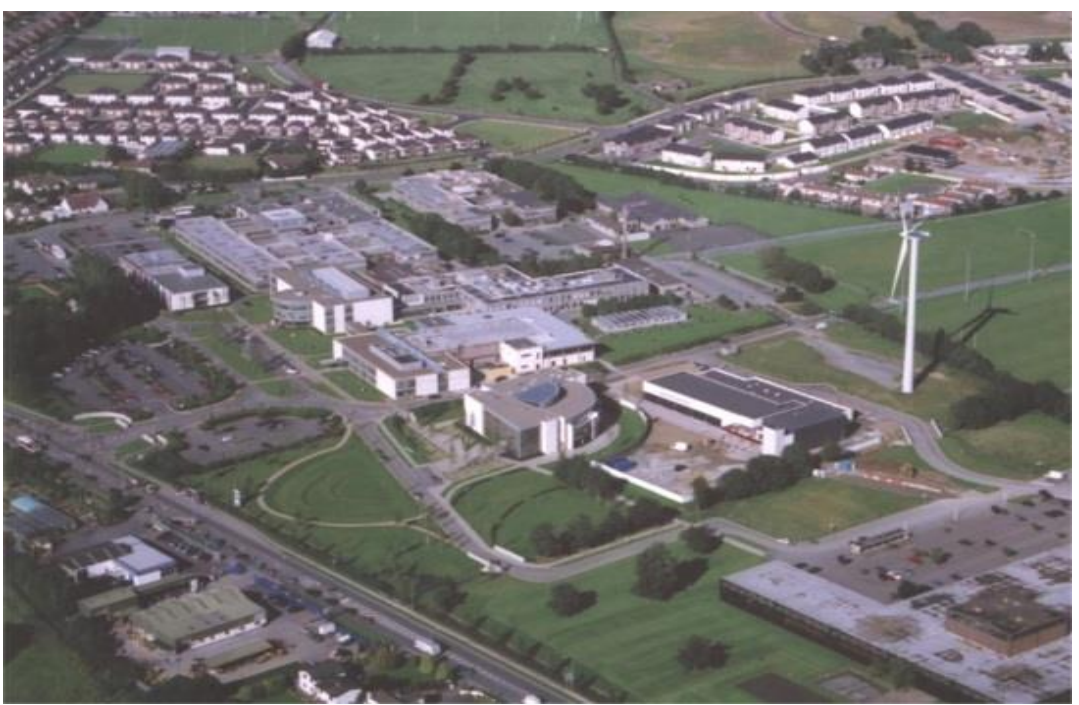

Fig. 1. Wind turbine at Dundalk Institute of Technology.

The site location on the east coast of Ireland is shown on the map in Fig 2. The wind turbine site elevation is 13 metres above sea level. The most significant elevated topographical features are identified in Table 1. With respect to the turbine location, the nearby obstacle features consist of various types and density of buildings at various distances from the wind turbine in each direction. Fig. 3 shows a plan view of the local obstacles around the turbine site. Table 2 lists the physical properties of the most significant buildings up to $\sim 1.5 \mathrm{~km}$ radius around the wind turbine. 


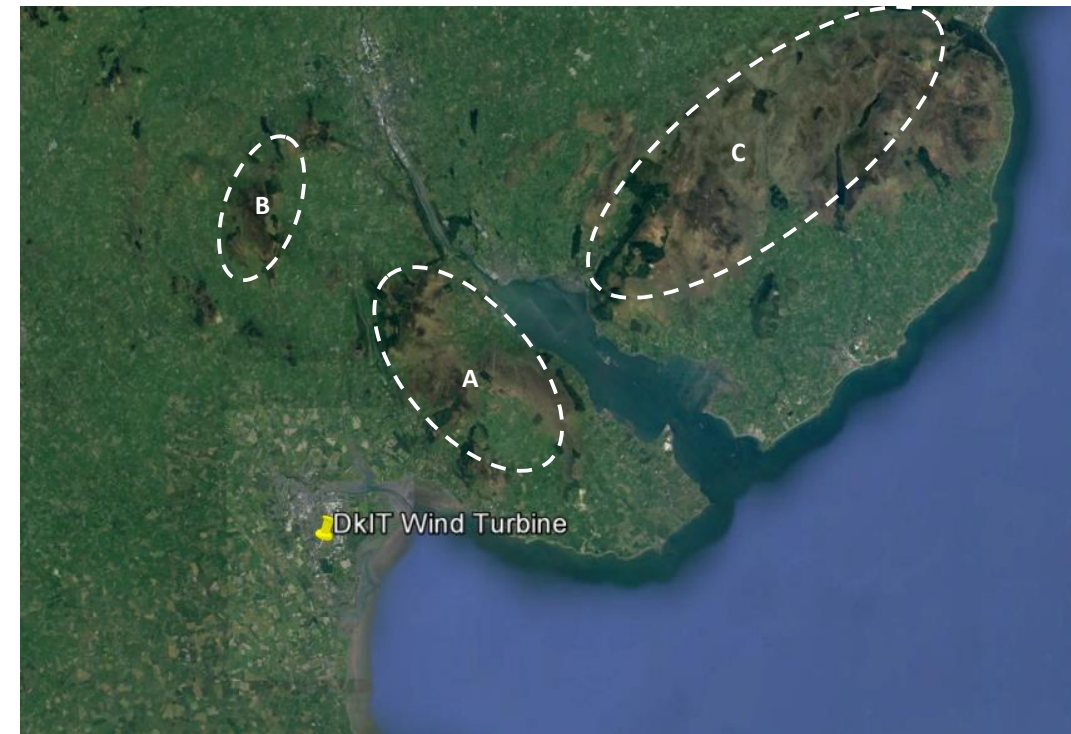

\begin{tabular}{lcl}
\hline \multicolumn{2}{l}{$\begin{array}{l}\text { Table } 1 \\
\text { Regional site features }\end{array}$} \\
\hline Site & Distance $[\mathrm{km}]$ & Elevation $[\mathrm{m}]$ \\
\hline $\mathrm{A}$ & $7.5-15$ & $75-563$ \\
$\mathrm{~B}$ & $13-18$ & $10-540$ \\
$\mathrm{C}$ & $17-40$ & $0-663$ \\
\hline
\end{tabular}

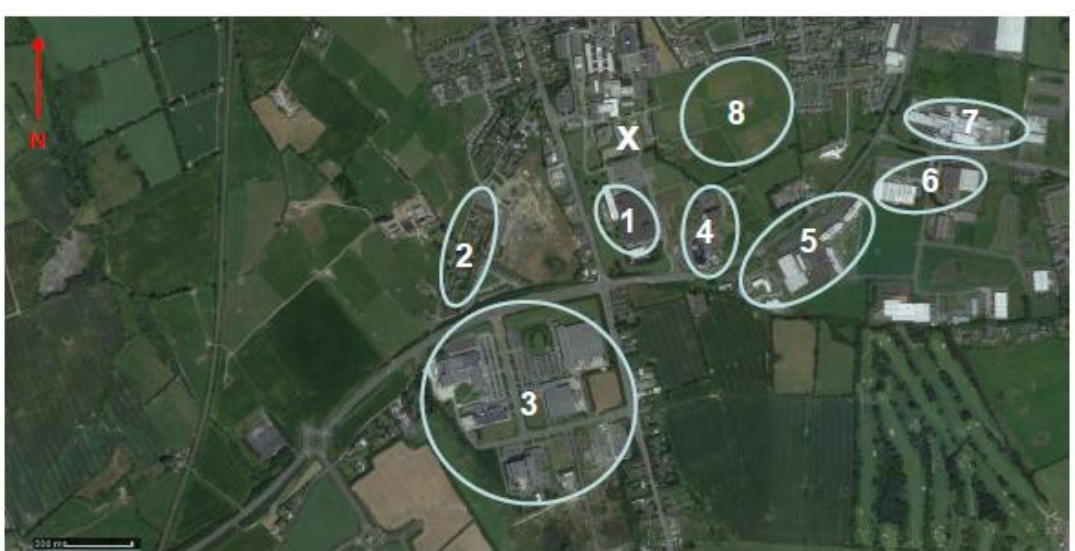

Fig. 3. Local obstacle features up to $1.5 \mathrm{~km}$ from site. $\mathbf{X}$ is the turbine location 


\begin{tabular}{|c|c|c|c|c|}
\hline \multicolumn{5}{|c|}{$\begin{array}{l}\text { Table } 2 \\
\text { Local site features }\end{array}$} \\
\hline Obstacles & Description & $\begin{array}{l}\text { Distance from } \\
\text { turbine }(\mathrm{m})\end{array}$ & $\begin{array}{l}\text { Height a.g.l } \\
(\mathrm{m})\end{array}$ & $\begin{array}{l}\text { Cross sectional } \\
\text { width as viewed } \\
\text { from wind turbine } \\
\text { (m) }\end{array}$ \\
\hline 1 & $\begin{array}{l}\text { Industrial } \\
\text { building }\end{array}$ & $151-315$ & 7 & 150 \\
\hline 2 & Row of houses & $487-728$ & 7 & 320 \\
\hline 3 & $\begin{array}{l}\text { Cluster of } \\
\text { industrial } \\
\text { buildings }\end{array}$ & $550-1100$ & 12 & 635 \\
\hline 4 & $\begin{array}{l}\text { Tall hotel (\& } \\
\text { student } \\
\text { accommodation } \\
\text { block) }\end{array}$ & $\begin{array}{l}335-420 \\
(241-312)\end{array}$ & $\begin{array}{l}47 \\
13\end{array}$ & $\begin{array}{l}70 \\
90\end{array}$ \\
\hline 5 & Office blocks & $520-670$ & $8-13$ & 420 \\
\hline 6 & $\begin{array}{l}\text { Industrial } \\
\text { buildings }\end{array}$ & $695-990$ & $6-7$ & 130 \\
\hline 7 & $\begin{array}{l}\text { Industrial } \\
\text { buildings }\end{array}$ & $770-1030$ & 10 & 130 \\
\hline 8 & Open field & $0-450$ & 0 & 350 \\
\hline
\end{tabular}

\subsection{Wind turbine system description}

The Vestas V52 wind turbine is a semi-variable speed system that consists of a $52 \mathrm{~m}$ diameter rotor, main shaft, gearbox, doubly fed induction generator (DFIG) and a $60 \mathrm{~m}$ tower. It has an active pitching system the blade pitch angles of all three rotor blades are controlled simultaneously by a hydraulic pith control system using the Vestas Opti-tip ${ }^{\mathrm{TM}}$ and Opti-speed ${ }^{\mathrm{TM}}$ control mechanisms. The control mechanisms aim to maximise energy capture at wind speeds below the rated power wind speed and to fix the power output to rated power at wind speeds above the rated power wind speed. In normal turbine operation the blade pitch angle is always below $20^{\circ}$. In a fault condition or pause/stop mode the blade pitch angle is fixed to approximately $86^{\circ}$. 


\subsection{SCADA data measurements}

The following parameters of interest, in 10 minute average values, are logged by the wind turbine SCADA system: wind speed, wind speed standard deviation, absolute wind direction, relative wind direction, rotor RPM, blade pitch angle, power output along with 10 minute minimum power output and maximum power output values. Separately, the accumulated total monthly energy production $(\mathrm{kWh})$, normal operating hours and hours in maintenance are captured from which the turbine availability for each year can be determined. Wind speed and direction data are measured by a two dimensional ultrasonic anemometer located on the turbine nacelle, as shown in Fig 4. It has a wind sampling rate of 20 milliseconds from which the 10-minutes data averages are logged. As this ultrasonic wind sensor is located behind the rotor there is an undetermined influence on wind flow from the upstream wind. Therefore the logged turbine 10-minute power output and corresponding electrical energy output with wind direction are also analysed.

\subsection{Irish wind atlas overview}

The Sustainable Energy Authority of Ireland (SEAI) commissioned the UK Met Office (Standen \& Wilson, 2015) to remodel the Irish Wind Atlas in 2013. It gives the end user 10 year mean wind speed values along with Weibull scale and shape factors at 8 different heights namely $20 \mathrm{~m}, 30 \mathrm{~m}$, $40 \mathrm{~m}, 50 \mathrm{~m}, 75 \mathrm{~m}, 100 \mathrm{~m}, 125 \mathrm{~m}$ and $150 \mathrm{~m}$ with a $100 \mathrm{~m}$ spatial grid resolution. It also can output 1 year of time series hourly mean wind speed and direction at the 8 heights with $1 \mathrm{~km}$ spatial resolution. The atlas is based on historic $4 \mathrm{~km}$ resolution data produced by NWP models designed to give long term, site and height specific wind climate information. The NWP models that are based on the UK met office's non-hydrostatic, fully compressible unified model (MetUM) and used ERA-Interim reanalyses data from 2001 to 2010 to model hourly wind components on a $4 \mathrm{~km}$ resolution grid. These were downscaled to a $1 \mathrm{~km}$ spatial grid to produce a $1 \mathrm{~km}$ grid of wind speed and direction data accounting for local site complexity using surface roughness values derived from the Corine land use data set (European Environment Agency, 2007). Scaled roughness correction (Howard \& Clark, 2007) is applied to adjust the $4 \mathrm{~km}$ winds over significant orography. Specific local obstacles (such as large buildings, cliffs, trees or operating wind turbines) are not modelled. 


\subsection{Wind resource analysis}

A representative year from the Irish Wind Atlas of hourly time series wind speed and wind direction data at a $50 \mathrm{~m}$ height a.g.l and a $1 \mathrm{~km}$ spatial resolution is used create wind roses at the turbine location and at locations east and west of the site to establish the prevailing wind direction and how it's influenced by local orography and local surface characteristics. These are compared with the measured wind rose based on 10-minute wind turbine SCADA data recorded between 2008 and 2015. The SCADA data is first checked for quality based on filtering within a range of realistic values to only include data where the wind turbine is in its normal mode of operation. Operational time fractions, wind speed distributions following the procedures of the (International Electrotechnical Commission, 2006) IEC 61400-12 wind turbine power performance standard. In addition, a 72 sector wind rose and directional wind power density in $5^{\circ}$ sectors are plotted to give a finer resolution of the directionality of wind flow and wind power density at the site. The turbulence intensity, power curve are plotted for 8 directions, each covering sector widths of $45^{\circ}$, in order to assess the directional variation of these parameters. From a siting and obstacle impact perspective on electrical energy performance to the end user, a novel approach of using an electrical energy rose (EER) is used. It is generated from measured 10-minute average power and wind direction values to create a 72 sector electrical energy output rose plot in $5^{\circ}$ sectors that shows the electrical energy $(\mathrm{kWh})$ output variation with the nacelle direction. The shape of the electrical energy rose is then used to give more distinct insights on how the turbine performs over a long (multi-annual) period in relation to the features in its surrounding environment. This is done by overlaying the electrical energy rose plot on the site plans at local and regional scales of Figs 3 and 2 respectively in combination with the corresponding physical dimensional and distances data given in Tables 2 and 1 respectively. Views from the turbine hub height in specific directions of interest are then used with the above information to give insights into the relative impact of site features on the wind turbine power curve, turbulence intensity variations and directional wind power density and directional electrical energy performance.

\subsubsection{SCADA data quality assessment}

A number of factors can impact upon quality and quantity of measured data available. These include turbine maintenance down times, turbine operational faults, grid outages, spurious data from sensor faults or sensor unavailability and data gaps due to communication network losses in the data logging system. A number of criteria are used to accept or reject 10-minute average data values based on the definition of an operational time fraction used the IEC 61400-12 wind turbine power performance standard. The operational time fraction (0) is defined as:

$O=\frac{T_{t}-T_{n}-T_{u}-T_{e}}{T_{t}-T_{n}-T_{e}} \times 100 \%$

where:

$\mathrm{T}_{\mathrm{t}}$ - total time period under consideration,

$\mathrm{T}_{\mathrm{n}}$ - known time when turbine is non-operational (e.g. fault conditions or loss of grid),

$\mathrm{T}_{\mathrm{u}}$ - time when status of turbine is unknown (e.g. gaps in or loss of logged data),

$\mathrm{T}_{\mathrm{e}}=$ excluded time in the analysis (e.g. turbine servicing), 


\subsubsection{Wind turbine availability}

Wind turbine availability is the proportion of time the turbine is available to generate electricity over a given time period irrespective of wind conditions. Times of non-availability are only considered for internal faults of the turbine itself resulting in non-operation of the turbine. Faults due to the grid or down times due to scheduled maintenance are not considered as downtimes due to the turbine itself. In the case of this system the turbine availability recorded by the SCADA system as is defined as:

$$
\text { Availability }(\%)=\frac{\text { Turbine OK }(\text { hrs })}{\text { Grid OK }(\text { hrs }) \text {-Scheduled Maintenance }(\text { hrs })} \times 100 \%
$$

\subsubsection{Directional energy output - Electrical Energy Rose (EER)}

The directional energy output from the turbine for given directional sector width $\theta_{w}$ can be expressed as summation of the product of power $\mathrm{P}_{\mathrm{j}}$ and time for each 10 minute time stamp $t_{\mathrm{j}, \theta}$ for the given directional sector width. An electrical energy rose can then be created for the whole $360^{\circ}$ view defined in equation (3)

$$
\mathrm{E}\left(\theta_{w}\right)=\sum_{j=1}^{j} \mathrm{P}_{\mathrm{j}}\left(\theta_{w}\right) \times t_{\mathrm{j}, \theta}
$$

It is the shape of the 72 sector with sector widths of $5^{\circ}$ that is used to determine the impact of the local building obstacles and regional terrain.

\section{Results}

\subsection{Wind Atlas estimates of wind and power density}

A representative year of hourly wind speed and directional data estimated by the Irish wind atlas at a height of $50 \mathrm{~m}$ is used to create wind roses at the turbine location and to the east and west of the site outside the region of local building obstacles. The locations of assessment are show in Fig. 4. Point (a) is $950 \mathrm{~m}$ to the south west of the wind turbine location (X) and point (b) is $2350 \mathrm{~m}$ to the north east of the turbine location. This is done to assess whether the calculated wind roses account for the surface roughness of the urban area and regional topography.

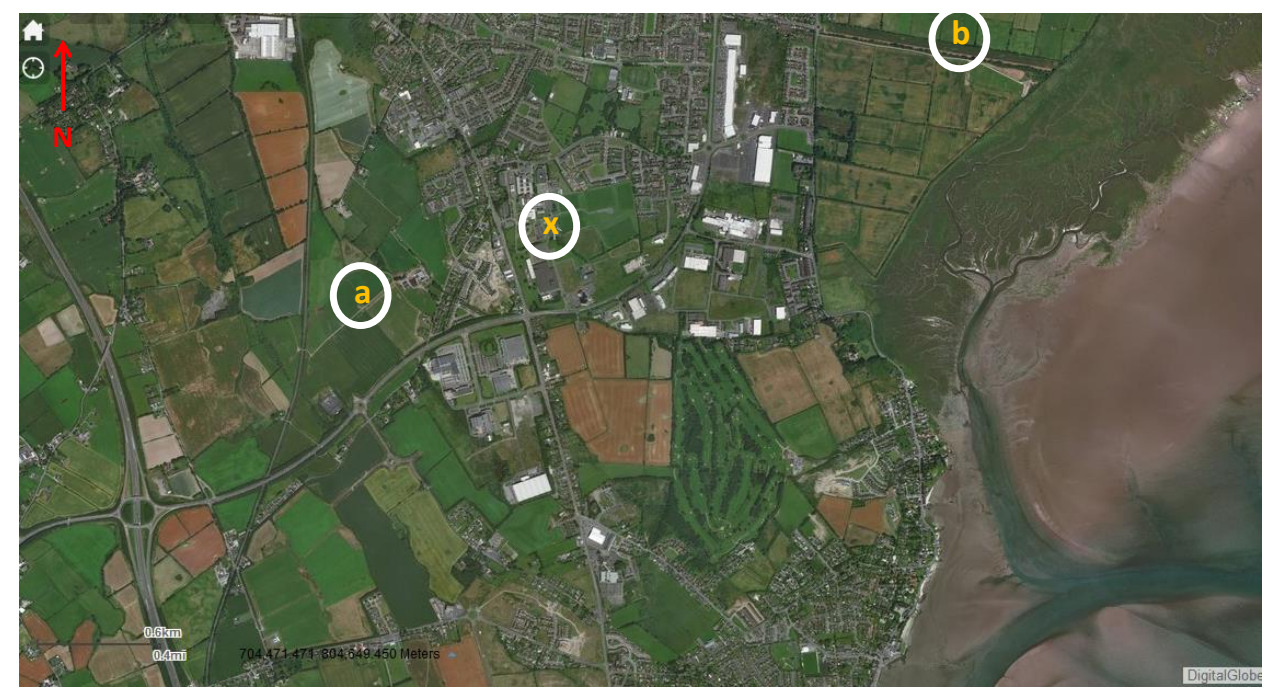

Fig. 4. Three locations of wind rose assessment using Irish wind atlas. $X=$ turbine location 
The $50 \mathrm{~m}$ wind roses for three locations are shown in Fig. 5. Point (a) is $950 \mathrm{~m}$ to SW of turbine location $\mathrm{X}$ while point (b) is $2350 \mathrm{~m}$ to NE.
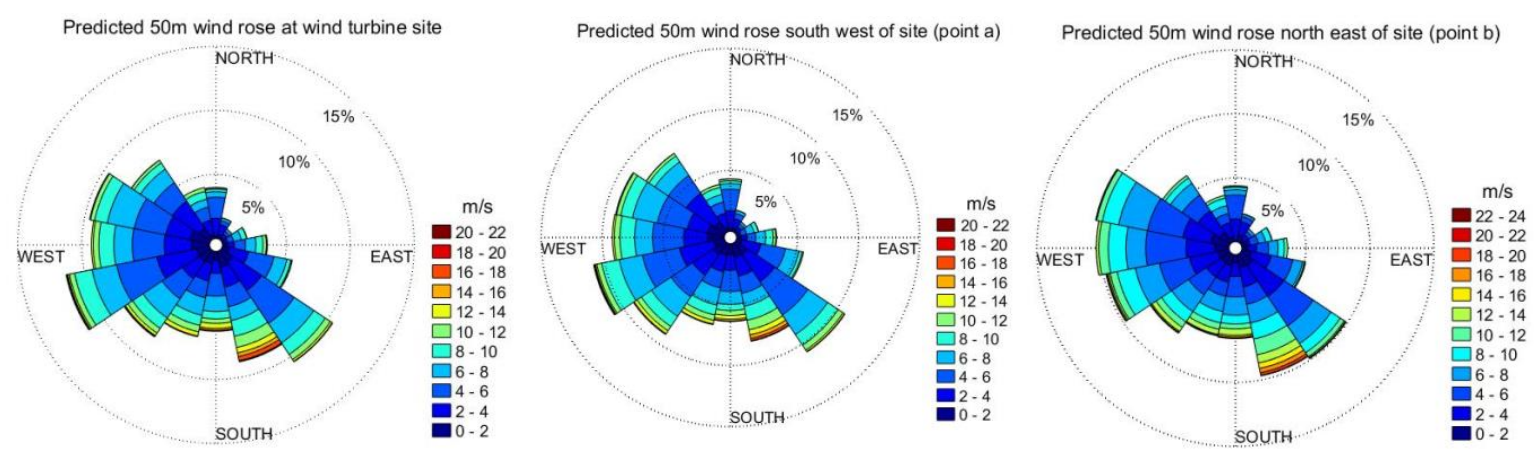

Fig. 5. Wind roses for the turbine location and at location at points $\mathrm{a}$ and $\mathrm{b}$

The wind roses at point (a) and the turbine site $(\mathrm{X})$ have quite similar shapes with small differences in wind speed from the west south west (WSW) to west north west (WNW) sectors. The wind rose at point (b) shows more reduced wind speeds from the south south west (SSW) to west south west (WSW) sectors. This indicates that the wind atlas is capturing the impact of higher surface roughness of the town on winds from the south west (SW) between point (a) and point (b) but not on specific local building obstacles between point (a) and the wind turbine site $(\mathrm{X})$. In all cases there is very little wind coming from the north (N) and northeast (NE) sectors indicating that local site roughness or building obstacle effects are not the significant reasons why wind are not coming from the north east. The hills $8 \mathrm{~km}$ (A in Fig.2) to the NE do not appear have wind speed up affect from this direction. Locations up to more than $10 \mathrm{~km}$ in the lee of hills (Vosper, 2004); (Sheridan \& Vosper, 2006) can, in some cases, experience various wind effects such as speed up, blocking or steering (changes in wind direction) depending on the shape of the hills and the prevailing wind directions. Wind speed up in the lee of hills can occur when winds are strong enough on the windward site to move air flow up and over hills where it cools, and its speed is enhanced on the leeward side due to the gravitational acceleration of the cooler (denser) air. If the winds on the windward side are not strong enough then blocking can occur or the air flow can be steered around the hill(s) depending on the shape of the hills and topography. In Ireland the general prevailing wind is SW to W, therefore the hills to the north east, because they end the coast are likely to be having a blocking affect from the NE and steering effect for northern easterly winds to the east (E) and southeast (SE) sectors. All three wind roses have a high wind speeds in the SE sectors, the strongest being at point (b). These are primarily due to onshore winds from the sea, particularly in the spring and early summer months, and may be enhanced by the steering of wind flow by the hills to the NE. At a local level the wind speeds in SSE at the wind turbine location and point (a) are lower due to local surface roughness effects not experienced by winds at point (b) from this direction. The results from multiannual measured wind turbine SCADA are given in the next section. 


\subsection{Data quality assessment}

From the recorded SCADA data both the annual turbine availability and 10-minute data availability from 2007 to 2015 are given in Table 3 .

\section{Table 3}

Annual wind turbine availability and 10_minute data availability

\begin{tabular}{lll}
\hline Year & $\begin{array}{l}\text { Turbine } \\
\text { Availability } \\
(\%)\end{array}$ & $\begin{array}{l}\text { 10-minute logged raw } \\
\text { data availability (\%) }\end{array}$ \\
\hline 2007 & 97.7 & 84.6 \\
2008 & 99.4 & 98.7 \\
2009 & 99.9 & 89.8 \\
2010 & - & 33.4 \\
2011 & 97.3 & 67.7 \\
2012 & 98.8 & 94.6 \\
2013 & 98.75 & 97.4 \\
2014 & 99.6 & 94.6 \\
2015 & 99.4 & 95.8 \\
\hline
\end{tabular}

In some years the lower availability of 10-minute logged data is due to faults in an external communication network that sends the 10-minute SCADA data to a remote computer. The turbine monthly total data values, from which turbine availability is assessed, is stored in the turbine controller itself independently of the external communications network. Only years with data availabilities greater than $90 \%$ are chosen for further analysis so as to minimise seasonal bias in the analysis. The resulting years used in the analysis are listed in Table 4. Using equation (1), known times when the turbine is not operational (Tn) and times when the turbine is in services mode (Te) are filtered from the data. The filtering is based on the status on blade pitch angle values. In fault mode or in service mode the wind turbine rotor is paused with a fixed blade pitch angle of $86^{\circ}$. In normal operation, when the wind turbine rotor is spinning, the pitch angle varies between $-1^{\circ}$ and $20^{\circ}$. Unknown turbine status (Tu) represents data unavailability. The equation is rearranged as shown in (4) to suit the available data so that only data that corresponds to normal operation of the turbine is carried forward for analysis.

$O=\frac{T_{t}-\left(T_{n}+T_{e}\right)-T_{u}}{T_{t}-\left(T_{n}+T_{e}\right)} \times 100 \%$

\section{Table 4}

Yearly Operational Time Fractions (O)

\begin{tabular}{lllll}
\hline Year & Tt(hrs) & Tn+Te (hrs) & Tu(hrs) & O (\%) \\
\hline 2008 & 8774 & 109.67 & 123.5 & 98.6 \\
2012 & 8774 & 294.5 & 485.5 & 94.3 \\
2013 & 8760 & 326.67 & 223 & 97.4 \\
2014 & 8760 & 162 & 470.67 & 94.5 \\
2015 & 8760 & 309 & 362.17 & 95.7 \\
\end{tabular}

Operational time fractions greater than $90 \%$ are considered for further analysis. 


\subsection{Directional wind analysis}

The 16 sector measured wind rose is shown in Fig 6. In the NE sectors there is good agreement between the wind turbine measured wind rose and the wind atlas predicted wind rose at the turbine location in Fig 5. However, there are some differences, requiring further investigation, in the SE, SW and NW sectors compared to wind rose predicted by the wind atlas. In particular the wind speeds to the SE, SSE and S measured at $60 \mathrm{~m}$ show reductions compared to the wind rose predicted by the wind atlas at $50 \mathrm{~m}$ at the turbine site. Due to the large quantity of data available and to assess finer directional features of wind flow a 72 sector wind rose in $5^{\circ}$ sectors is shown in Fig. 7 and the directional wind power density in Fig. 8.

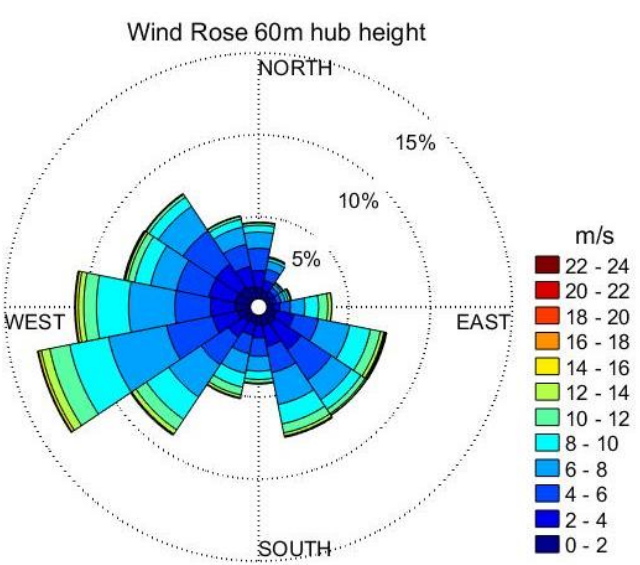

Fig. 6. Wind rose in $11.25^{\circ}$ sectors

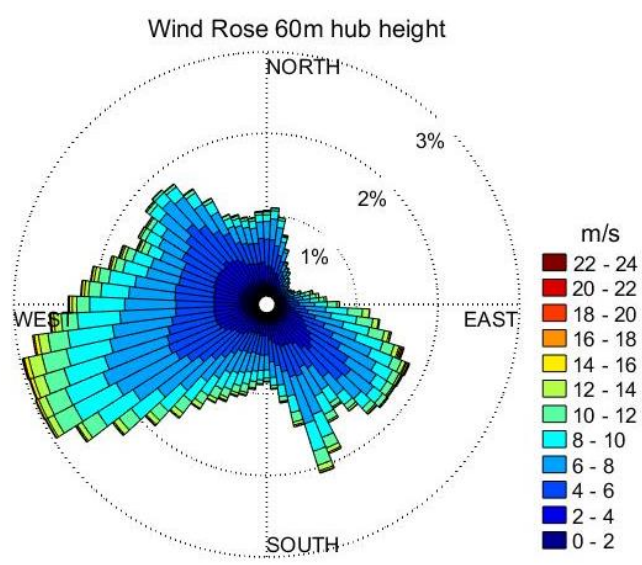

Fig. 7. Wind rose in $5^{\circ}$ sectors

\section{Directional Wind Power Density}

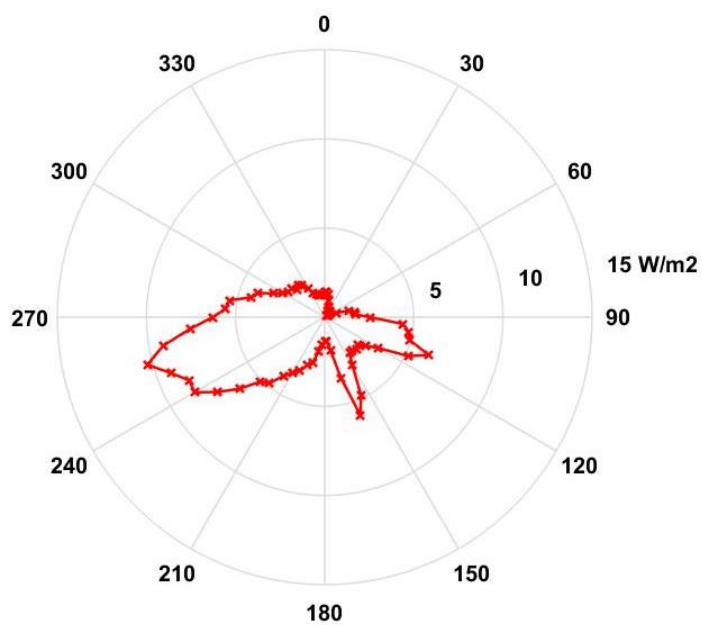

Fig. 8. 72 sector directional wind power density i.e. directional breakdown of the $244.5 \mathrm{~W} / \mathrm{m} 2$ site average

The site average wind power density over the multiannual time frame is $244.5 \mathrm{~W} / \mathrm{m} 2$. The directional breakdown of this shows that higher wind power densities appear from the west southwest sectors. There are distinct reductions of wind speeds, wind occurrences and corresponding wind power densities in the S to SW sectors, NE sectors and the SE sectors. Referring to the plan view of Fig 3 it can be seen the local buildings occupy those area in the $S$ to SW sectors and the SE sectors where wind flow is reduced. There is very little wind in the north 
east sectors confirming that these hills $\sim 8 \mathrm{~km}$ to the northeast are not having a wind speedup effect from the NE. The behaviour of the turbine in terms of power performance seems vary with direction in response to different wind inflow conditions from different directions due the influences of local and regional obstacles.

\subsection{Directional power curve and turbulence analysis}

Fig. 9 shows the power curves from the SCADA data analysis following IEC 61400-12 methods for 8 directional sectors. Despite being active pitched controlled machine the power curves appear to deviate the most above wind speeds of about $10 \mathrm{~m} / \mathrm{s}$. The best curve above $10 \mathrm{~m} / \mathrm{s}$ occurs for wind coming from the east (i.e. $90^{\circ}$ ) looking towards the coast in a direction where there are few local building obstacles. Poorer power curves occur for directions from $180^{\circ}$ and $225^{\circ}$ where there are more significant building obstacles. Other directions, such as $315^{\circ}$, show poorer comparative power performance between $10 \mathrm{~m} / \mathrm{s}$ and $12 \mathrm{~m} / \mathrm{s}$, improving again at higher wind speeds. This could be explained by the turbine control mode changing from variable speed to fixed speed and variable blade pitch operation at these wind speed. An analysis of turbulence intensity with direction, shown in Fig. 10, indicates that directions with lower turbulence intensity corresponds to direction of better power performance above wind speeds of $10 \mathrm{~m} / \mathrm{s}$. Interestingly, at lower wind speeds less than $8 \mathrm{~m} / \mathrm{s}$ the power curves in the higher turbulence sectors are marginally better that those in the lower turbulence sectors. This indicates that the wind turbine can extract more power from higher turbulent wind flows at lower wind speeds due to the rotor being better able to respond to the wind speed variations at lower wind speeds.

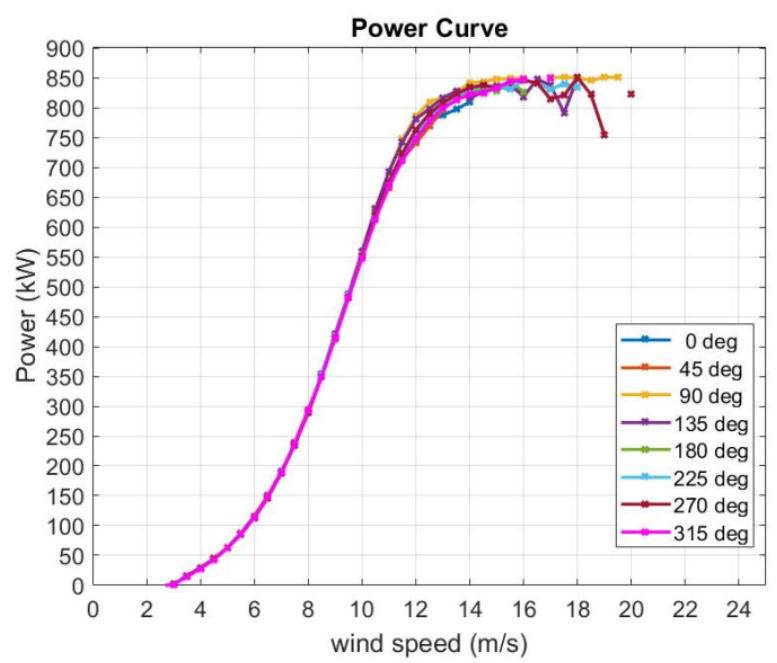

Fig. 9. Directional power curves

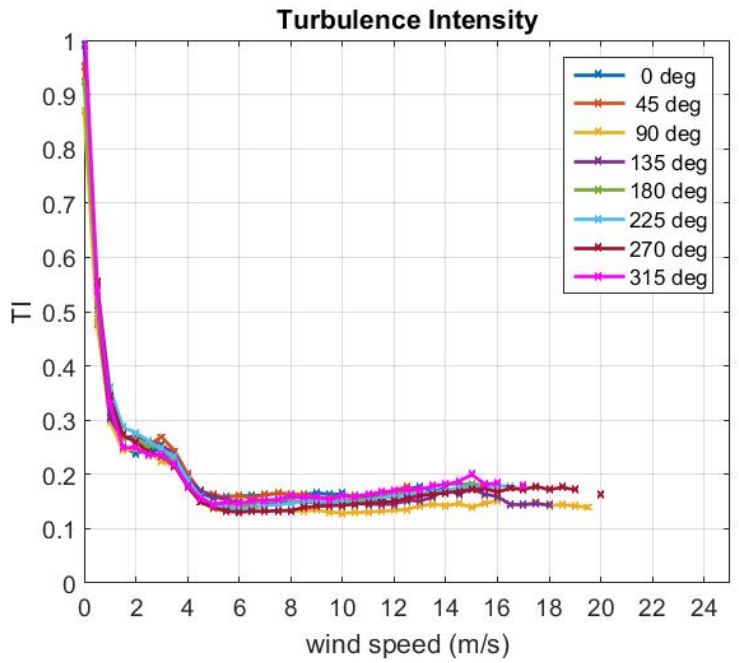

Fig. 10. Directional power curves

End users of behind the meter wind turbines in urban locations are most likely to be interested in the electrical energy (kWh) output. Further analysis is carried out in next section.

\subsection{Electrical Energy Rose (EER) and site feature analysis}

A new method of analysis is proposed called the Electrical Energy Rose (EER) which illustrates the directions of greatest electrical energy yield. To gain further insights into the local site features on the energy performance an EER in 72 sectors defined by equation (3) is created which shows the directions where the useful electrical energy comes from. A plot of the EER is shown in Fig 11. Its shape has distinctive directional features showing the directional sectors where the energy performance of the wind turbine is high and low. Reduced energy output directional sectors are observed in the south (S), south southwest (SSW), southeast (SE), north 
$(\mathrm{N})$ and northeast (NE) directions while better energy output directional sectors appear in west (W), south southeast (SSE) and north southeast (NSE) directions. This EER show subtle but important differences to the wind rose (Fig. 7) and the power density rose (Fig. 8) and illustrates the highest energy yielding sectors for this turbine at this site.

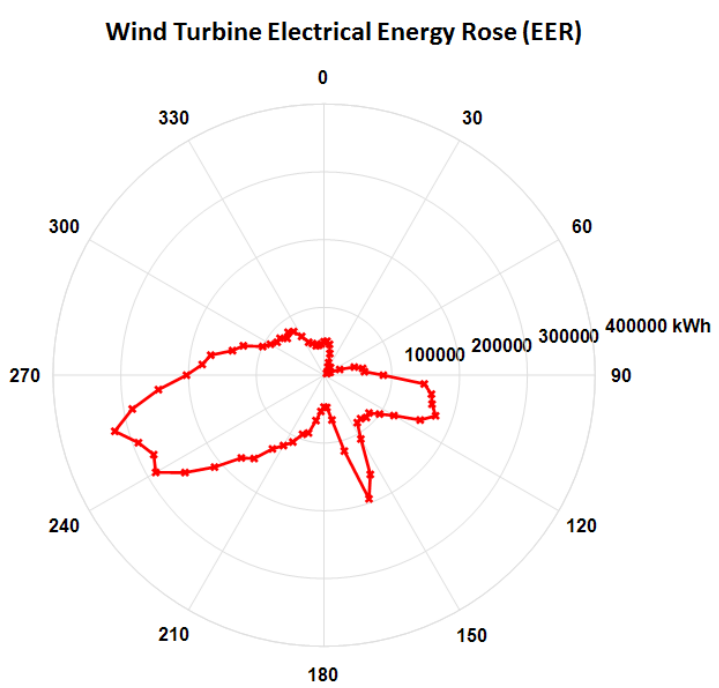

Fig. 11. Wind turbine EER in $5^{\circ}$ sectors

\subsection{Electrical Energy Rose (EER) and site obstacles}

An overlay of the EER on the local map of Fig. 12 reveals how local obstacles may be impacting on the directional energy performance of the wind turbine. From approximately $170^{\circ}$ to $210^{\circ}$ there is a much reduced energy output while high energy performance sectors occur from $150^{\circ}$ to $170^{\circ}$ and $85^{\circ}$ to $120^{\circ}$ while the highest energy performing sector is from $220^{\circ}$ to $280^{\circ}$. Very little energy output comes from north east sectors $0^{\circ}$ to $90^{\circ}$. If the wind rose predicted by the wind atlas was used there would be a significant overestimation of energy yield in the $170^{\circ}$ to $210^{\circ}$ sector.

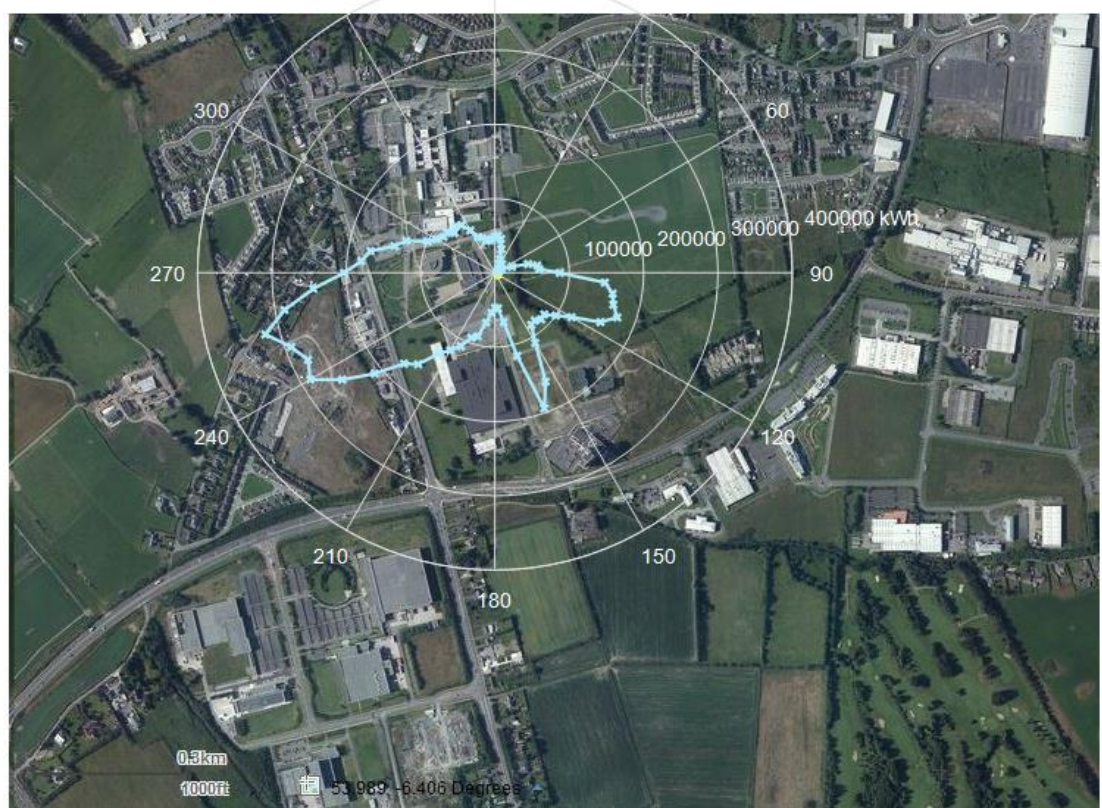

Fig. 12. Wind turbine EER overlaid at wind turbine location on local site plan 
531 On closer examination of the overlaid EER with the local obstacles described in Fig 3 (and Table2), and in combination views from the $60 \mathrm{~m}$ hub height of the wind turbine, give the following observations; Fig. 13 shows the view from the wind turbine in the direction from $170^{\circ}$ to $210^{\circ}$ across obstacle Nos. 1 and 3 where there is a much reduced electrical energy output.

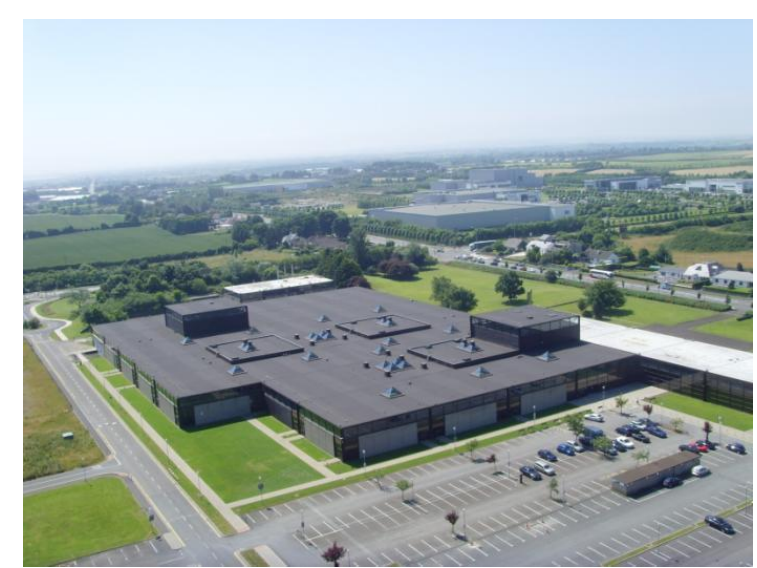

The wind turbine has a hub height of $60 \mathrm{~m}$ and the majority of these buildings are $7 \mathrm{~m}$ to $12 \mathrm{~m}$ in height (i.e. no more than $20 \%$ of the hub height) with a distance of $150 \mathrm{~m}$ to $1100 \mathrm{~m}$ from the turbine location. From the literature this should not have as great an influence as it does. The narrower high energy performance sectors from $150^{\circ}$ to $170^{\circ}$ are observed and the view from the turbine hub height, in Fig 14 shows an opening (including a road) between the $47 \mathrm{~m}$ high hotel (obstacle No .4) $335 \mathrm{~m}$ away and obstacle No. 1. It may point to channelling or steering effects of wind flow between these the tall narrow hotel and the low broad building(s) of obstacle No.1 and with possible influence from obstacle No.3 to far right.

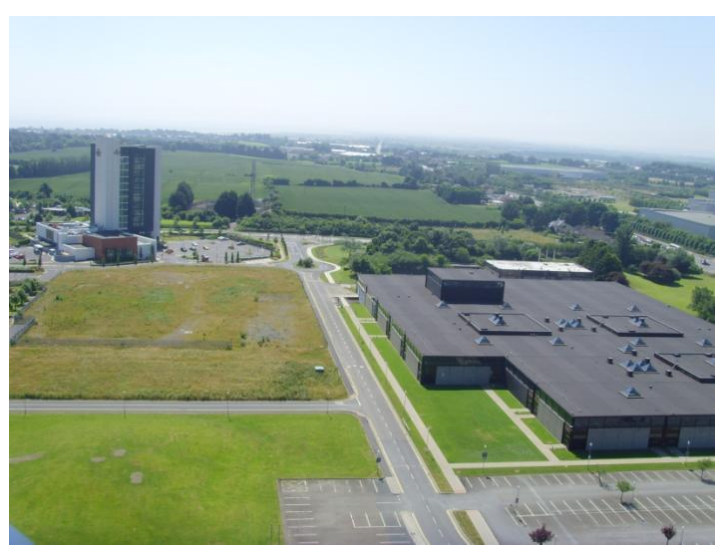

Fig. 14. Wind turbine hub height view looking $150^{\circ}$ to $170^{\circ}$ (Obstacles: No.4 tall hotel to left, No.1 to right)

Energy reduction is again seen in the $110^{\circ}$ to $150^{\circ}$ directional sectors due to the tall hotel and additional buildings further to the south east. This view of these additional buildings to the south east is shown in Figs 15 (obstacle No. 4) and Fig 16 (obstacles Nos 5 and 6) which have heights from $8 \mathrm{~m}$ to $13 \mathrm{~m}$ and are $52 \mathrm{~m}$ to $990 \mathrm{~m}$ from the turbine location. 


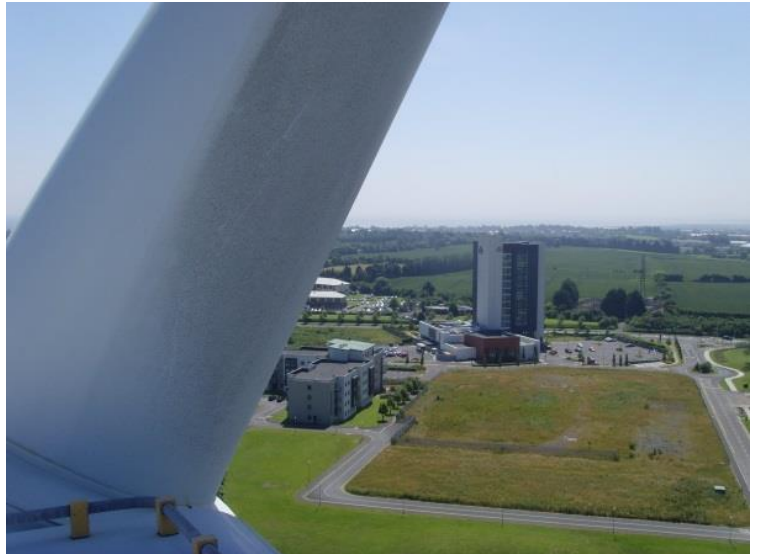

Fig. 15. Wind turbine hub height view looking $130^{\circ}$ to $150^{\circ}$ (Obstacles: No.4)

Higher energy appears in $95^{\circ}$ to $120^{\circ}$ sectors which appear to fall between obstacles Nos. 5 and 7 which are $770 \mathrm{~m}$ to $1030 \mathrm{~m}$ away from turbine. Between these obstacles is a lower building $7 \mathrm{~m}$ in height and a road that runs to the coast. This view shows the fetch to the east coast with a gap between building obstacles No 5 and 7 allowing onshore winds on to the site. This is also a direction from which the turbulence intensity was lower and the turbine power curve was better at higher wind speeds. It again appears indicates the energy reducing impact of low rise building on the turbine energy output and the influence of gaps between building for better energy performance.

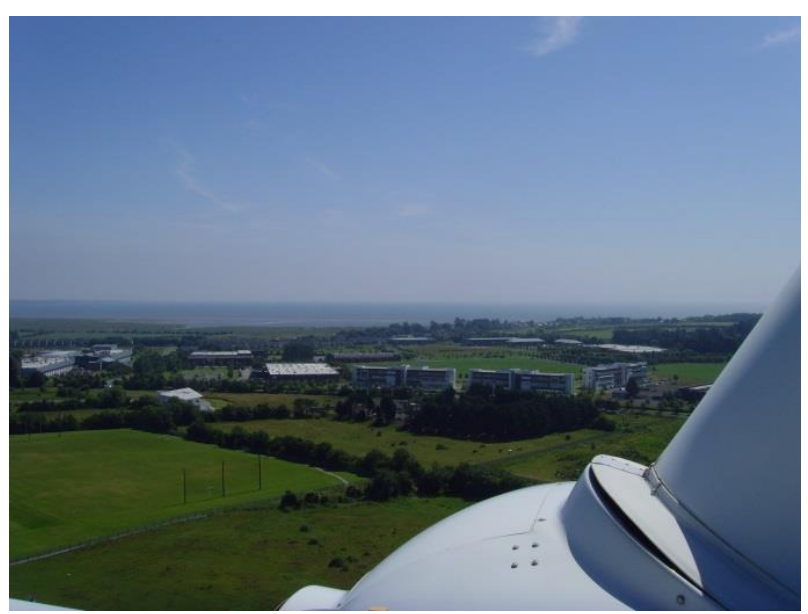

Fig. 16. Wind turbine hub height view looking 95० to $130^{\circ}$ (Obstacles: Nos.5, 6 and 7)

Energy performance in the north and north easterly sectors appear to be drastically reduced with no obvious shaping of the EER by local obstacles. There is more open space out to $450 \mathrm{~m}$ to the east a northeast of the wind turbine (area 8 in Table 1). When viewed from the turbine hub height as shown in Fig 17 the hills (Site A in Table 1) with elevations approximately $650 \mathrm{~m} \mathrm{a}$ distance of $8 \mathrm{~km}$ away, pointing to the sheltering impact of the hills on a regional or mesoscale are being experienced by the wind turbine at its lower elevation. This is predicted from the wind atlas. 


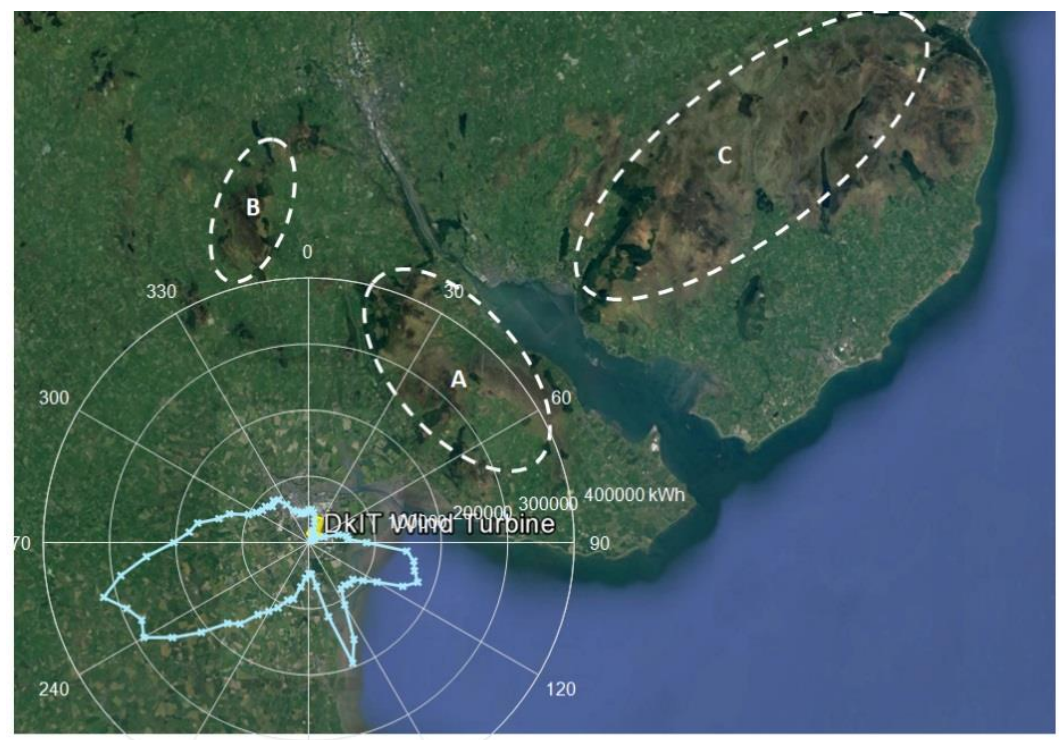

Fig. 18. Wind turbine electrical energy rose overlaid on local site plan

An overlay of the EER on the regional plan of Fig 2 is shown in Fig 18. It becomes apparent that the hills to the north east from $0^{\circ}$ to $90^{\circ}$, regions A and B in Table 1 shape the electrical energy rose in these directions with higher energy performing easterly sectors from the sea primarily influenced by the local building obstacles as describe previously. In fact, in directions from $90^{\circ}$ to $330^{\circ}$ there are no significant onshore topographical features in the region implying that the electrical energy rose is being significantly shaped these directions by local building obstacles.

Shown in Fig. 19 the town of Dundalk is to the north with hills (Site B in Table 1) in background approximately $15 \mathrm{~km}$ away Most of the town consists of house and commercial building less than $10 \mathrm{~m}$ in height that come close to the turbine location. Energy remains much reduced broadly across the NW to NE sectors as the results of mesoscale impacts of hills combined with local impact of town in the northerly directions. 
601

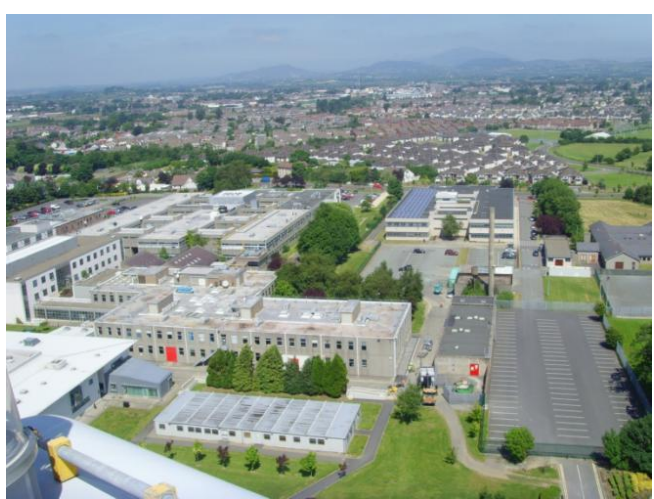

Fig. 19. Wind turbine hub height view looking $330^{\circ}$ to $30^{\circ}$ (Site A and B Hills of $650 \mathrm{~m}$ elevation 15km away)

Finally, the view of the predominantly higher the energy sectors from $220^{\circ}$ to $290^{\circ}$ are shown in Fig 20. These sectors have a good wind fetch with open fields beyond $\sim 500 \mathrm{~m}$ upwind including a motorway upwind that runs in line the oncoming wind flow. A row of dwelling houses (obstacles No. 2) $487 \mathrm{~m}$ to $728 \mathrm{~m}$ away upwind that has a height of approximately $7 \mathrm{~m}$. These have a shaping impact on the electrical energy rose. Energy spikes on either side of the row of houses suggest that winds are channelling either side of and reducing over the houses.

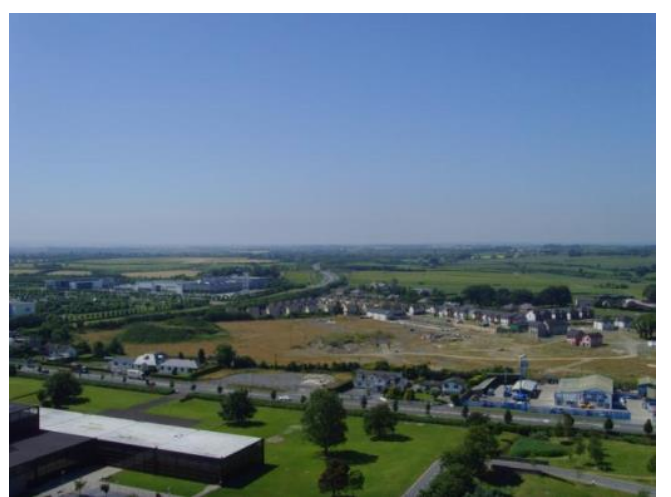

Fig. 20. Wind turbine hub height view looking $220^{\circ}$ to $290^{\circ}$ (Obstacle: No. 2)

\section{Discussion}

The results show that the power performance of a turbine is dependent both on the local site feature impact on wind flow and behavioural response of the wind turbine system itself to different wind flow conditions. To help determine what this means from an end user point of view a directional output energy analysis and it relation to site features is carried out. The approach of using a 72 sector EER overlaid on local and regional plans reveals more strikingly how the energy performance can be significantly impacted by local and regional features. It shows that building obstacles approximately $20 \%$ of the turbine hub height and up to $1.5 \mathrm{~km}$ away can have a significant energy blocking effect e.g. $12 \mathrm{~m}$ high industrial buildings while a smaller impact is observed for building between $10 \%$ and $20 \%$ of hub height. Simple reported rules of thumb (Ishugah, et al., 2014) that wind flow is reduced up to $2 \mathrm{H}$ the obstacle height and up to $20 \mathrm{H}$ away from the obstacle don't conform with the finding here.

(Peña, et al., 2016) performed full scale LiDAR full-scale lidar-based shelter observations on a single fence that was $30 \mathrm{~m}$ wide $3 \mathrm{~m}$ high and $0.04 \mathrm{~m}$ thick for different porosities and wind inflow conditions. The shelter impact was highest at 1.46 fence heights and observed up to a maximum 11 fence heights downwind. The results do not match so well to the findings here, possibly due the fence being a thin (i.e. 2D like) body in the direction of wind flow i.e. unlike a large 3D obstacle like a building. The width of the building obstacles in this study and 
corresponding directional sector angle width as viewed from the turbine location appear to have energy reduction indicating that low broad building obstacles can have a significantly bigger energy reducing impact compared to taller narrower buildings. This may be due to low broad buildings forming wider localised boundary layers thereby increasing wind shear and/or steering of the wind flow in other directions, while wind flow may move around taller narrower buildings. This tends to agree with the flow characteristics around the rectangular bodies with various aspect (height to width) ratios reported by (Gu \& Lim, 2012) who found that the that transverse width has a more substantial impact of the surface pressure around bluff bodies compared to the longitudinal length.

Channelling of flow in gaps between building and along roads running parallel to the oncoming wind direction from the SSE of the site is observed to enhance energy performance but the turbulence intensity is higher. This may be due to gusting as a result of pressure differences around buildings that form the channel and the dissipation of vortices in the flow downwind of the channel in the direction of the wind turbine. Mesoscale effects, in this case primarily blocking due to low winds, of hills $8 \mathrm{~km}$ to $15 \mathrm{~km}$ away with an elevation of $\sim 650 \mathrm{~m}$ are observed to the north and north east of the site. Such features in a $15 \mathrm{~km}$ to $20 \mathrm{~km}$ radius be considered in the initial visual screen of a potential site for a behind the wind meter project. The study suggests that large energy users considering a large scale behind the meter project stages should, in the initial feasibility stages, consider regional topography within a $20 \mathrm{~km}$ radius of the proposed turbine location as there is potential for wind blocking, speed up or steering depending on general prevailing wind direction of the region. Local obstacles within at least a 1 $\mathrm{km}$ radius should be considered. Broad obstacles with a height of $20 \%$ of turbine tower height or greater up to $1.5 \mathrm{~km}$ away in prevailing wind direction(s) can have a negative impact on energy performance. If obstacles greater than $20 \%$ of proposed tower height occupy more than $30 \%$ of the field of view in prevailing wind direction the study suggests increasing the tower height or to reconsider the viability of the project location.

\section{Conclusions}

It has been shown, based on the analysis of measured multi-annual 10-minute SCADA data, that the energy performance of large scale wind turbine deployed in an autoproducer (behind the meter) depends on number of local site and regional factors along with the behaviour of the turbine system itself. A novel approach of using an electrical energy rose (EER) overlaid on local and regional plans appear to indicate that peri-urban building layout of up to at least 1.5 $\mathrm{km}$ should be considered accounting for building obstacles with heights of more than $20 \%$ of hub height and that regional terrain within a $20 \mathrm{~km}$ radius of the turbine location should be considered in micro-siting assessments. If obstacles greater than $20 \%$ of proposed wind turbine hub height occupy more than $30 \%$ of the field of view in prevailing wind direction the study suggests increasing the tower height or to reconsider the viability of the project location. In general the study shows that the both the power and energy performance of large wind turbines is complex peri-urban areas need further research to gain a better understanding of wind inflow characteristics at peri-urban sites along with the behaviour of medium to large scale wind systems in these environments. This should involve the improvement and choice of flow models for site specific analysis and field validation against wind measurements and with power and electrical energy performance data sets of operating turbines. The use of remote wind sensing devices such as LiDAR would enable direct measurements and assessments of obstacles on wind flow at a practicable level. This would help improve existing model validation of wind flow characteristics and wind turbine performance and help enable the standardisation of wind resource and energy assessment approaches in peri-urban environments. Such studies would also benefit mechanical loading assessments for international standards development and in the justification of setback distances both from energy and social acceptance points of view. 
"This research was supported by the European Union's INTERREG VA Programme, managed by the Special EU Programmes Body (SEUPB).”

\section{References}

1 Bardal, L. M. Sætran, L. R. \& Wangsness, E., 2015. Performance Test of a 3MW Wind Turbine - Effects of Shear and Turbulence. Energy Procedia, 80, pp. 83 - 91.

2 Beaucage, P., Brower, M. C. \& Tensen, J., 2014. Evaluation of four numerical wind flow models for wind resource mapping. Wind Energy, 1 2, 17(2), pp. 197-208.

3 Bechmann, A. et al., 2011. The Bolund Experiment, Part II: Blind Comparison of Microscale Flow Models. BoundaryLayer Meteorology, 8, 141(2), p. 245.

4 BELCHER, S. E., JERRAM, N. \& HUNT, J. C. R., 2003. Adjustment of a turbulent boundary layer to a canopy of roughness elements. Journal of Fluid Mechanics, Volume 488, pp. 369-398.

5 Cheng, Y., Lien, F. S., Yee, E. \& Sinclair, R., 2003. A comparison of large Eddy simulations with a standard k- $\varepsilon$ Reynolds-averaged Navier-Stokes model for the prediction of a fully developed turbulent flow over a matrix of cubes. Journal of Wind Engineering and Industrial Aerodynamics, 91(11), pp. 1301-1328.

6 Coceal, O. \& Belcher, S. E., 2004. A canopy model of mean winds through urban areas. Quarterly Journal of the Royal Meteorological Society, 130(599), pp. 1349-1372.

7 Cooney, C., Byrne, R., Lyons, W. \& O'Rourke, F., 2017. Performance characterisation of a commercial-scale wind turbine operating in an urban environment, using real data. Energy for Sustainable Development, 36, pp. 44 - 54.

8 da Costa, J. C. L., Castro, F. A., Palma, J. \& Stuart, P., 2006. Computer simulation of atmospheric flows over real forests for wind energy resource evaluation. Journal of Wind Engineering and Industrial Aerodynamics, 94(8), pp. 603 - 620. 9 Dadioti, R. \& Rees, S., 2017. Performance of Detached Eddy Simulation applied to Analysis of a University Campus Wind Environment. Energy Procedia, 134, pp. 366-375.

10 Dadioti, R. \& Rees, S., 2017. ScienceDirect Performance of Detached Eddy Simulation applied to Analysis of a University Campus Wind Environment. Energy Procedia, 134(00), pp. 366-375.

11Desmond, C. J., Watson, S. J. \& Hancock, P. E., 2017. Modelling the wind energy resource in complex terrain and atmospheres. Numerical simulation and wind tunnel investigation of non-neutral forest canopy flow. Journal of Wind Engineering and Industrial Aerodynamics, 166, pp. 48 - 60.

12 Drew, D. R., Barlow, J. F. \& Cockerill, T. T., 2013. Estimating the potential yield of small wind turbines in urban areas: A case study for Greater London, UK. Journal of Wind Engineering and Industrial Aerodynamics, 115, pp. 104 111.

13 Drew, D. R., Barlow, J. F., Cockerill, T. T. \& Vahdati, M. M., 2015. The importance of accurate wind resource assessment for evaluating the economic viability of small wind turbines. Renewable Energy, 77, pp. 493 - 500. 14 ELMokadem, A. A., Megahed, N. A. \& Noaman, D. S., 2016. Systematic framework for the efficient integration of wind technologies into buildings. Frontiers of Architectural Research, 5(1), pp. 1 - 14.

15 European Environment Agency, 2007. Corine Land Cover 2000 seamless vector data.

16 Fields, J., Tinnesand, H. \& Baring-Gould, I., 2016. Distributed Wind Resource Assessment: State of the Industry, Golden, USA: NREL/TP-5000-66419

17 Finnigan, J., 2009. The Urban Canopy and the Plant Canopy. Reading, UK, s.n.

18 Franke, J. et al., 2011. The COST 732 Best Practice Guideline for CFD simulation of flows in the urban environment: a summary. International Journal of Environment and Pollution, 44(1-4), pp. 419-427..

19 Grieser, B., Sunak, Y. \& Madlener, R., 2015. Economics of small wind turbines in urban settings: An empirical investigation for Germany. Renewable Energy, 78, pp. 334 - 350.

$20 \mathrm{Gu}$, D. \& Lim, H.-C., 2012. Wind flow around rectangular obstacles and the effects of aspect ratio. Shanghai, China, International Association for Wind Engineering.

21 GWEC, 2016. GLOBAL WIND STATISTICS, s.l.: s.n.

22 Gylling, N. et al., 2015. Comparison of Resource and Energy Yield Assessment Procedures 2011-2015: What have we learned and what needs to be done?. Proceedings of the EWEA Annual Event and Exhibition.

23 Hanrahan, B. L., Lightbody, G., Staudt, L. \& G. Leahy, P., 2014. A powerful visualization technique for electricity supply and demand at industrial sites with combined heat and power and wind generation. Renewable and Sustainable Energy Reviews, 31, pp. 860-869.

24 Heath, M. A., Walshe, J. D. \& Watson, S. J., 2007. Estimating the potential yield of small building-mounted wind turbines. Wind Energy, 10(3), pp. 271-287.

25 Herrmann-Priesnitz, B., Calderón-Muñoz, W. R. \& LeBoeuf, R., 2015. Effects of urban configuration on the wind energy distribution over a building. Journal of Renewable and Sustainable Energy, 7(3), p. 33106.

26 Hildreth, L. \& Kildegaard, A., 2009. Avoided demand charges and behind-the-meter wind: insights from an application at the University of Minnesota. Wind Energy, 12(4), pp. 363-374.

27 Howard, T. \& Clark, P., 2007. Correction and downscaling of NWP wind speed forecasts. Meteorological Applications, 14(2), pp. 105-116. 
28 International Electrotechnical Commission, 2006. IEC 61400-12-1:2006 Wind turbines - Part 12-1: Power performance measurements of electricity producing wind turbines. s.l.:s.n.

29 Ishugah, T. F., Li, Y., Wang, R. Z. \& Kiplagat, J. K., 2014. Advances in wind energy resource exploitation in urban environment: A review. Renewable and Sustainable Energy Reviews, 37, pp. 613 - 626.

30 Lantz, E. et al., 2016. Assessing the Future of Distributed Wind: Opportunities for Behind-the-Meter Projects, Golden, USA: NREL/TP-5000-66419NREL/TP-6A20-67337.

31 Manwell, J. F., McGowan, J. G. \& Rogers, A. L., 2009. Wind Energy Explained: Theory, Design and Application. 2nd ed. :Wiley.

32 Mertens, S., 2006. Wind Energy in the Built Environment Concentrator Effects of Buildings. s.l.:Multi-Science. 33 Millward-Hopkins, J. T. et al., 2013. Assessing the potential of urban wind energy in a major UK city using an analytical model. Renewable Energy, 60, pp. 701 - 710.

34 Peña, A., Bechmann, A., Conti, D. \& Angelou, N., 2016. The fence experiment - full-scale lidar-based shelter observations. Wind Energ. Sci, Volume 1, pp. 101-114.

35 Peterka, J., Meroney, R. \& Kothari, K., 1985. Wind flow patterns about buildings. Journal of Wind Engineering and Industrial Aerodynamics, 1 8, 21(1), pp. 21-38.

36 Pitteloud, J.-D. \& Gsänger, S., 2017. 2017 Small Wind World Report Summary, s.l.: s.n.

37 Sheridan, P. F. \& Vosper, S. B., 2006. A flow regime diagram for forecasting lee waves, rotors and downslope winds. Meteorol. Appl, Volume 13, pp. 179-195.

38 Standen, J. \& Wilson, C., 2015. Remodelling the Irish national onshore and offshore wind atlas, s.l.: s.n.

39 Staudt, L., 2006. Developments and Cost Benefits of the Campus Wind Turbine at Dundalk Institute of Technology. Dublin.

40 Sunderland, K., Conlon, M. \& Conlon, M. F., 2010. Estimating the Yield of Micro Wind Turbines in an Urban Environment: A Methodology. s.l., URL, pp. 1-6.

41 Sustainable Energy Authority of Ireland (SEAI), 2015. Irish Wind Atlas. [Online] Available at: http://maps.seai.ie/wind/

42 Tabrizi, A. B., Whale, J., Lyons, T. \& Urmee, T., 2014. Performance and safety of rooftop wind turbines: Use of CFD to gain insight into inflow conditions. Renewable Energy, 67, pp. 242 - 251.

43 Toja-Silva, F. et al., 2015. Roof region dependent wind potential assessment with different $\{$ RANS $\}$ turbulence models. Journal of Wind Engineering and Industrial Aerodynamics , 142(), pp. 258 - 271.

44 van Kuik, G. A. M. et al., 2016. Long-term research challenges in wind energy - a research agenda by the European Academy of Wind Energy. Wind Energy Science, 1(1), pp. 1-39.

45 Vosper, S., 2004. Inversion effects on mountain lee waves. Quarterly Journal of the Royal Meteorological Society. 46 Wang, B., Cot, L. D., Adolphe, L. \& Geoffroy, S., 2017. Estimation of wind energy of a building with canopy roof. Sustainable Cities and Society, 35, pp. 402 - 416.

47 Yang, A.-S.et al., 2016. Estimation of wind power generation in dense urban area. Applied Energy, 171, pp. 213 230.

48 Zendehbad, M., Chokani, N. \& Abhari, R. S., 2016. Impact of forested fetch on energy yield and maintenance of wind turbines. Renewable Energy, 96(Part A), pp. 548 - 558.

49 Zhang, M. H., 2015. Wind Resource Assessment and Micro-siting: Science and Engineering. :Wiley. 